\title{
Politique
}

Politique

\section{Économie du Québec et de ses régions de Diane-Gabrielle Tremblay et Vincent Van Schendel, Montréal, Éditions Saint-Martin, 1991, 649 p.}

\section{André Turcotte}

Numéro 22, automne 1992

URI : https://id.erudit.org/iderudit/040738ar

DOI : https://doi.org/10.7202/040738ar

Aller au sommaire du numéro

Éditeur(s)

Société québécoise de science politique

ISSN

0711-608X (imprimé)

1918-6584 (numérique)

Découvrir la revue

Citer ce compte rendu

Turcotte, A. (1992). Compte rendu de [Économie du Québec et de ses régions de Diane-Gabrielle Tremblay et Vincent Van Schendel, Montréal, Éditions

Saint-Martin, 1991, 649 p.] Politique, (22), 159-161.

https://doi.org/10.7202/040738ar d'utilisation que vous pouvez consulter en ligne.

https://apropos.erudit.org/fr/usagers/politique-dutilisation/ 


\section{Économie du Québec et de ses régions}

de Diane-Gabrielle Tremblay et Vincent Van Schendel, Montréal, Éditions Saint-Martin, 1991, 649 p.

II est bon de se pencher sur un des éléments-clé de l'épanouissement de la société québécoise : le dynamisme du secteur économique. La force du "Québec Inc." se veut souvent un baromètre de la confiance des Québécois en leur capacité d'affirmation nationale et les auteurs d'Économie du Québec et de ses régions explorent la dynamique du développement économique du Québec.

Comme I'indiquent Danielle-Gabrielle Tremblay et Vincent Van Schendel, au cours du vingtième siècle, l'économie du Québec n'a cessé de se transformer. Ce n'est qu'en 1961 que le secteur tertiaire est devenu la principale source d'emplois au Québec. Cependant, trente ans plus tard, un peu plus de sept Québécois sur dix $(71 \%)$ sont employés dans ce secteur. Le passage du Québec pré-industriel à l'ère moderne ne s'est pas effectué sans heurts mais le produit final se veut une grande réalisation dont les Québécois sont fiers. Habituellement, lorsque cette évolution est étudiée, l'État reçoit une attention qui masque l'importance d'autres acteurs moins connus. Tremblay et Van Schendel veulent contribuer à rétablir un équilibre.

Le cadre méthodologique adopté par les auteurs rend l'ouvrage particulièrement intéressant. Comme il vient d'être noté, le rôle de l'État est souligné mais ne constitue pas le point central de l'analyse. Tremblay et Van Schendel se concentrent sur cinq grands axes thématiques qui expliquent le développement économique du Québec. Après un aperçu historique et des considérations 
méthodologiques et théoriques essentielles à une compréhension plus complète des thèmes centraux de cet ouvrage, les auteurs se penchent sur la structure économique du Québec.

Économie du Québec et de ses régions se tourne alors vers les différents aspects de l'activité économique québécoise sous l'angle de l'emploi, de la population et des revenus. Les secteurs primaire, secondaire et tertiaire, la croissance démographique et économique, la tertiarisation et la féminisation du marché du travail, et la répartition des revenus et la pauvreté sont les principaux thèmes explorés. Ensuite, les auteurs se penchent sur la situation économique dans les régions. Dans cette section, la structure économique de la région de Montréal et son possible déclin, ainsi que les régions économiques de l'Est du Québec, le Saguenay, I'Abitibi-Témiscamingue, la Côte-Nord, la Mauricie, l'Estrie, Québec et l'Outaouais sont analysés, peut-être trop sommairement, à l'intérieur d'une problématique de développement de l'activité économique. À travers cet aperçu, le lecteur prend conscience des pôles de développement à l'intérieur de la province et de la dépendance des régions.

Enfin, la cinquième partie est consacrée à l'analyse des principaux acteurs responsables de la croissance économique du Québec. Diane-Gabrielle Tremblay et Vincent Van Schendel identifient quatre participants qui méritent l'attention du lecteur. En premier lieu, les auteurs discutent du dynamisme du développement local et communautaire et de ses principales caractéristiques ainsi que le rôle joué par les organisations locales dans l'économie québécoise. Puis, les entreprises et l'entreprenariat, le syndicalisme ainsi que les institutions financières et monétaires sont intégrés dans cette analyse globale de l'économie du Québec.

Ce livre est certes ambitieux de par l'ampleur des sujets discutés mais il réussit à éviter les pièges inhérents à la rédaction d'un manuel de base. À vouloir trop en présenter, les auteurs se devaient de ne pas tomber dans le superficiel et la banalité. Au contraire, ce livre discute de thèmes importants de façon intelligente et intéressante. II serait trop facile $d$ 'isoler certains aspects qui auraient pu être développés plus avant, mais une telle critique serait la réflexion des goûts personnels du lecteur plutôt que d'une lacune réelle de l'ouvrage.

Bref, ce manuel nous présente les forces et faiblesses de l'économie du Québec. Toutefois, le livre de Diane-Gabrielle Tremblay et Vincent Van Schendel se veut plus qu'un traité d'économie. Les auteurs nous offrent une réflexion sur l'avenir du Québec. Dans les années 60, l'évolution du Québec s'est 
orchestrée autour du transfert de l'énergie nationaliste de la religion vers la politique. L'impact de ce réalignement a reçu beaucoup d'attention dans la littérature. Cependant, les années 80 ont amené un autre réalignement, cette fois, de la politique vers l'économie. Autant que la langue, le dynamisme économique est devenu une caractéristique nationale à laquelle les Québécois s'identifient. Le livre Économie du Québec et de ses régions contribue à mieux comprendre ce phénomène.

André Turcotte

Université de Toronto 